\title{
Improving adherence in chronic airways disease: are we doing it wrongly?
}

Non-adherence to medicines is a significant clinical and financial burden, but successful strategies to improve it, and thus bring about significant improvements in clinical outcome, remain elusive. Many barriers exist, including a lack of awareness amongst some healthcare professionals as to the extent and impact of non-adherence and a dearth of skills to address it successfully. Patients may not appreciate that they are non-adherent, feel they cannot disclose it or underestimate its impact on their health in the short and longer term. In describing the evidence-based frameworks that identify the causal factors behind medicines taking (or not taking) behaviours, we can start to personalise interventions to enable individuals to make informed decisions about their treatments and thus overcome real and perceived barriers to adherence.

\section{Educational aims}

- To understand the underlying principles of why a patient may or may not take medicines as agreed.

- To choose targeted interventions to support better adherence.

Adherence has been defined by the World Health Organization (WHO) as "the extent to which a person's behaviour corresponds with agreed recommendations from a health care provider" [1]. They suggest that in the developed world, medicines adherence in chronic conditions is $\sim 50 \%$, yet despite acknowledgement that non-adherence in healthcare is a clinically significant and financially costly burden, it has not changed substantially over the past 50 years [1, 2]. In this issue of Breathe, colleagues [3, 4] have eloquently described how adherence should be measured and the sequelae of poor adherence, and in this paper we complete the triumvirate of medicines adherence with suggested methods to improve it.
Cite as: d'Ancona G, Weinman J. Improving adherence in chronic airways disease: are we doing it wrongly? Breathe 2021; 17 : 210022. 
Unfortunately, there is no quick fix to improving adherence, rather "state-of-the-art" strategies need to target the patient, the provider, and the healthcare system [1,5]. While higher order interventions affecting health policy, organisation and financing of care, and care quality programmes will likely play direct and indirect roles in promoting adherence [6], that is outside the scope of this paper, rather we will focus on the discussion of barriers to adherence for healthcare providers (HCP) and patients. We will describe theories from health psychology to first understand why our patients do not take their medicines as directed, then using examples of their application in clinical research, will suggest interventions to support its improvement. "Adherence" is used to describe the patients' medicines use process as a whole, but it can further delineated into three distinct domains [7]:

- initiation (starting treatment)

- execution (having initiated therapy, taking it as directed)

- persistence (maintenance of the treatment long term)

Where this differentiation is particularly pertinent, we will bring the reader's attention to which is being discussed.

\section{Barriers to adherence: healthcare professional factors}

\section{Are my patients adherent?}

To improve adherence, we must first acknowledge that non-adherence is present to a considerable degree in patients under our care, then respond appropriately to it. The misunderstanding by HCPs of non-adherence as an akratic act or "weakness of will" has been described previously in the context of people with sleep disorders [8] and helps us appreciate that non-adherence does not result from someone having the wrong values, rather that in spite of knowing the "best" course of action they may decide to do something else. It helps us understand why "educating" the patient alone is unlikely to improve adherence and that patients may be reluctant to "admit to" non-adherence, particularly when asked in a direct way. In an illustration of this, ENGEL et al. [9] found that patients were five times more likely to disclose non-adherence in response to being asked how often they missed a drug dose compared with those who were asked directly if they took their medication as they should.

Similarly, patients may deny non-adherence in favour of the socially desirable "adherent" response. A "no-blame" approach by the HCP, wherein we acknowledge that non-adherence is common and do not judge the person for it, is more likely to elicit an honest admission of non-adherence or expression of their doubts and concerns regarding treatment [10]. We should remember that addressing non-adherence is not about getting patients to take more medicines per se, rather it is the process of identifying an inability to take the treatment, exploring the reasoning for them wanting to take the therapy or not, and in bringing this together, helping the individual make informed decisions for their own benefit.

Clinicians may consider detection of nonadherence to be beyond their professional remit, ask questions that elicit a defensive reaction from the patient, or simply avoid the issue as they do not have the skills or the time to manage it [11]. A US study by MedDINGs et al. [12] investigated physician assessment of patient adherence to blood pressure medicines compared with prescription refill records. They found that doctors in the study failed to recognise non-adherence in more than half of patients, but more startlingly, they often increased antihypertensive medications even when they suspected non-adherence. Indeed, the recent Organisation for Economic Cooperation and Development (OECD) working paper included their concerns regarding clinicians being unaware of the extent and impact of the adherence problem in their patients [13].

The phenomenon of underestimating nonadherence is not restricted to physicians. A study by CLYNE et al. [14] investigated the views of over 3000 HCPs (including physicians, nurses and pharmacists) who provided care to adults in a primary care setting in 10 European countries. It aimed to assess their perception of patient adherence across all three adherence domains: initiation, execution and persistence at 1 year. HCPs were asked to answer questions on two distinct populations with a chronic illness: "patients in their country" generally and "their own patients" specifically. Interestingly, they found that participant's perceptions of medicines adherence differed significantly when considering their own patients in comparison to general patients. HCPs perceived their patients to be more likely to initiate therapy, less likely to adhere to the regimen and more likely to demonstrate persistence after 1 year. The authors hypothesised as to the potential reasons for these differences (including HCPs preferentially looking to confirm suspected good adherence, rather than seek poor adherence), and concluded that an unconscious optimistic bias among HCPs was likely to create an overestimate of medication adherence.

This tendency to overestimate medicines adherence in one's own patients is likely caused by a number of factors but reflects another common issue in decision making: sampling bias. That is, adherence may be higher in patients who attend appointments and, not surprisingly, clinicians base their judgements on these patients rather than those who have stayed away [14]. Whatever the reason for this inaccuracy, if clinicians are not 
aware of the extent of the adherence problem, they will be unlikely to routinely enquire about adherence and even less likely to offer adherence support.

\section{How good is good enough?}

We know that medicines not taken appropriately are unlikely to have the desired effect, but in considering the need to improve adherence, another difficulty arises: what level of adherence are we hoping to achieve? Ideally, targets should be derived from clinical evidence, based on optimal outcomes and minimal adverse effects. In 2000, Paterson et al. [15] robustly described the case for protease inhibitor therapy adherence needing to be $\geq 95 \%$ for patients with HIV infection to optimise virological outcome. Similarly, in the seminal clinical trials investigating tuberculosis management, the assignment of "adequate adherence" was defined as $76 \%-80 \%$ of intended doses taken $[16,17]$ and allowed appropriate comparison and assessment of response. Interestingly, such was the strength of influence of non-adherence on outcome (for the patient and in avoiding resistance), that it has been suggested that clinical trials should examine more than one threshold for non-adherence (e.g. $80 \%$ and $95 \%$ ) to more robustly assess efficacy [18]. When describing adherence to continuous positive airway pressure (CPAP) two figures are considered: the number of hours of CPAP use per night and the number of nights that this target is achieved. While KRIBBs et al. [19] may have arbitrarily defined optimal CPAP adherence as at least $4 \mathrm{~h}$ of CPAP administered on $70 \%$ of days monitored, this has been accepted as the standard target and adherence interventions explored to reach it [20]. This pragmatism and consistency of approach has unfortunately not been adopted in airways diseases, and as yet, no such threshold has been universally agreed for inhaled therapy use. This is a seemingly frustrating failing, but as we move towards more clinically appropriate biomarkerled care, perhaps we should not request a onesize-fits-all figure, rather a more accessible way to achieve the individualised maximal response/ minimal adverse effect level of inhaler use [21, 22]. The effects of such a strategy in the run-in phase of a clinical trial would be particularly interesting.

\section{Barriers to adherence: patient factors}

Patients may be non-adherent for many reasons, and these can vary between individuals and in the same individual over time. However, in better understanding the underlying causes, we can employ strategies to militate against them. Broadly speaking, adherence can be classified as unintentional or intentional. Unintentional non-adherence is considered a passive process whereby patients do not take their medicines due to circumstances outside their control (e.g. forgetfulness, not understanding the instructions or an inability to pay for therapy). Whereas intentional non-adherence is defined as an active decision by the individual to not take treatment (thought to be driven by patient beliefs about their treatment, disease and prognosis, as well as their objective experiences with medications). While traditionally it was felt that unintentional non-adherence was driven by demographic characteristics (e.g. younger age, female gender), in truth, patients may exhibit both types concurrently, one can lead to the other, and the boundaries between the two may not be as distinct as previously considered. For example, someone is less likely to forget a medicine they perceive to be essential than one considered unimportant [23].

Airways disease is predominantly managed by inhaled therapies (categorised as pressurised metered dose inhalers (PMDI) or dry powder inhalers (DPI)) and this mode of delivery adds a unique complexity to achieving optimal adherence. It is estimated that as many as $80 \%$ of people with asthma are unable to use their prescribed device correctly [24, 25], with similar figures reported in COPD [26]. Poor inhaler technique is considered "unintentional", but unfortunately it is not clear how clinicians can most effectively intervene to improve it [27-29] and the interventions needed to improve the technique of people with asthma appear different to those necessary for those with COPD [26, 30]. CusHen et al. [31] described the adherence of patients with COPD as one of four inhaler use clusters: 1) regular use/good technique, 2) regular use/poor technique, 3) irregular use/good technique and 4) irregular use/poor technique. They found that not only were patient outcomes different depending on their "cluster" but reinforced the idea that the interventions to increase adherence should also be different. In a final twist, in isolation the inhaler technique observed with either type of device may be satisfactory, but the co-prescribing of a DPI and a pMDI adversely affects patient ability to use either type of inhaler optimally with resultant impacts on clinical outcomes in COPD [32], and asthma in both children [33] and adults [34]. This suggests that it is crucial not only to check and improve inhaler technique, but where possible rationalise multiple prescriptions to one device or the other.

In focusing attention on detecting nonadherence, we have rather neglected what we should do when we find it. To date, most research on interventions to promote adherence has been by health psychologists and focused largely on understanding and then attempting to modify patient behaviour. Several theoretical models have been developed to explain and try to predict adherence to prescribed treatment. They 
encompass patients' beliefs about health, their beliefs about illness and the treatment prescribed, but increasingly, more comprehensive frameworks recognise that medicines taking behaviour is multifaceted and must incorporate assessment of a wide variety of factors. Indeed, the WHO suggested that the most promising methods to support adherence use a combination of strategies tackling patient education, behavioural skills, selfrewards, social support and telephone follow-up [1]. Hence by believing that health behaviours are modifiable, the hope is that in understanding the types and causes of non-adherence, one can tailor interventions to address them.

The earliest approaches for understanding and improving adherence were based on attempts to provide better information and improve recall [35]. The assumption was that communication about treatment with patients was often limited and/ or of poor quality, so patients did not understand what they were required to do and subsequently forgot. Since then, from the large number of studies investigating reasons for non-adherence, a wide range of possible factors have been identified. These have been incorporated into a framework [36], which identifies three broad groups of causal factors and proposes that people need the capability $(\mathrm{C})$, opportunity $(\mathrm{O})$ and motivation $(\mathrm{M})$ to perform a particular behaviour (B) (COM-B). COM-B has been applied to a number of health contexts including treatment adherence [37] and this is outlined below.

Capability is the patient's psychological and physical ability to engage in a behaviour. When applied to treatment adherence, psychological ability can include the patient's capacity to understand, remember and plan to take their treatment, whereas physical ability may refer to the level of dexterity required to use a device, such as an inhaler. While better communication and understanding can improve adherence to a degree for patients in whom this is their main adherence barrier, there is clear evidence that providing reminders does not really help people who have already become non-adherent [38]

Opportunity covers the physical and social factors external to the individual that make the behaviour possible or prompt it. Physical factors include ease of access to the healthcare system, financial constraints, the complexity of the regimen, and even the taste of the medicine itself. Social opportunity factors include the quality of support from healthcare providers and from family and friends, who can encourage or discourage medicines taking, and the wider social context (e.g. religious or cultural beliefs held by the patient). Interventions involving support from HCPs have been shown to improve adherence, but unless these strategies improve motivation, they are unlikely to be successful [39].

Motivation is the want or need to perform the behaviour in the context of competing demands at that moment. It is a key driving force for engaging (or not) in any health-related behaviour, including treatment adherence. There are two broad groups of motivational factors: reflective and automatic. Reflective factors include the patient's beliefs about medicines (e.g. the perceived need to use the treatment as prescribed, the anticipated or experienced negative impact of side-effects) and the condition being treated (e.g. the patient's beliefs about the perceived seriousness or controllability of their condition). Where a clinician has not set realistic expectations for the patient with respect to a treatments potential benefits, onset of action or side-effects, it is logical that if a patient takes their medicines as advised initially, then experiences adverse effects or indeed, no effect, that they then decide not to take further doses. The failure here is in that decision not being communicated to the clinician. Automatic motivational factors include the patient's mood, their habits and other decisionmaking heuristics. Medicines taking may have been incorporated into daily activities, for example medicines are taken with breakfast or associated with setting their alarm clock in the evening; however, when the routine is disrupted the cue to action may be missed resulting in the medicines not being taken.

All three groups of factors in COM-B are important to ensure a behaviour will be carried out, but at an individual patient level, it is crucial to identify their key barrier(s) in order to support or change their adherence behaviour. To do this, the HCP will need to ask open-ended questions to uncover the factors responsible for that person's adherence problems. This can be supplemented or facilitated by using simple screening questionnaires, which allow the patient to indicate their main adherence challenges. A recent example of this is the brief pre-consultation screener: "Making medicines work for you" [40]. It consists of a simple checklist where the patient indicates whether they are experiencing any of seven problems with their medicines, rather than asking them directly about their adherence. It is drawn from the COM-B framework, so includes items which assess capability (I cannot manage so many medicines), opportunity (I cannot afford either the time or money to get the medicines) and motivation (I am not sure if the medicine is really helping me). A pilot study among patients with diabetes found that the screener could identify a range of medicines-related issues and that $88 \%$ of the sample indicated at least one issue, contrasting with the relatively small numbers who typically disclose non-adherence verbally [40]. Table 1 provides examples of the COM-B framework applied to respiratory medicine.

COM-B is not the only framework to support adherence in practice. The Perceptions and Practicalities Approach (PAPA) [11] also aims to support the understanding of medicines taking behaviours and offer practitioners a suite of multilayered pragmatic interventions that can be tailored 
Table 1 Capability, opportunity and motivation to perform a behaviour (COM-B) [37] model applied to patients with respiratory disease and suggested solutions

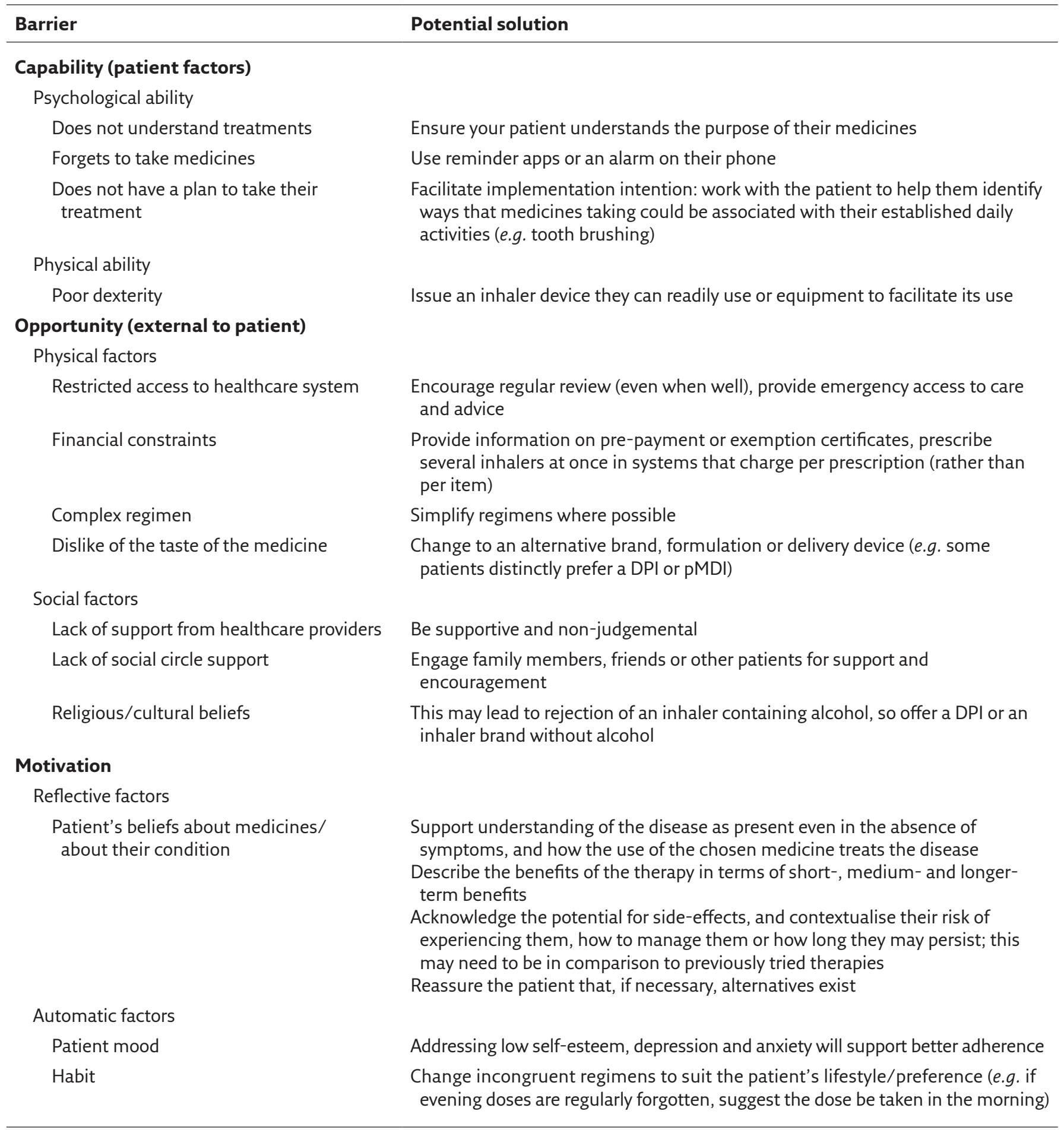

to an individual. It is based on the premise that two key and inextricably linked factors are essential for adherence: motivation and ability. It considers the patient's decision-making process (predominantly by exploring their beliefs around disease, treatment necessities and concerns) and marries that with the practicalities of taking therapy as directed. Its underlying message is that when practical barriers are removed, adherence only occurs when the value of a particular therapy overcomes the person's concerns about taking it. This is a necessity and concerns model, where necessity beliefs (effectively answering the question "why do I need to follow this treatment to achieve my aim", and more subtly "how much of this can I get away with not taking?") are evaluated alongside concerns. 
Concerns encompass side-effects (those anticipated or experienced previously), the disruptive effects of taking a medicine on daily life (for example it being an unwelcome daily reminder of the presence of disease) and often the misconception that taking treatments regularly may lead to dependence, accumulation (and therefore adverse effects) or that efficacy will diminish over time.

An interesting and relatable factor described by HoRne et al. [11, 41], is that of a patient's perception of "sensitivity" to the effects of medicines, with many believing themselves to be more sensitive than others. This could manifest itself as them being more prone to side-effects or as needing less treatment to derive the beneficial effect. In this case, the patient's strategy of non-adherence may be to minimise harm to themselves. To address these necessities, concerns and practicalities, PAPA reinforces the need for a no-blame approach to empower patients to discuss non-adherence openly and honestly. While conceptual framework models form the basis of interventions, in practice, do they deliver improvements in adherence and does this improvement positively affect clinical outcome?

\section{Interventions tested for impact on adherence}

A Cochrane systematic review spanning several chronic diseases identified the following factors as having a positive influence on adherence: using simpler dosing regimens, having pharmacist involvement in care, provision of reminders/ cues, education delivered with self-management training, and to a lesser degree, financial incentives [42]. The benefits of a systematic approach to improving overall lung health and medicines adherence by HCPs in general have been described elsewhere [43, 44], as have the data to support specific pharmacist-delivered interventions in asthma [45-47] and those emerging in COPD [48-51]. The studies described below focus on evaluating the interventions themselves rather than who provided them.

\section{Asthma education and self-management}

Apter et al. [52] aimed to test the impact on adherence and outcomes associated with standard asthma education (SAE) versus an individualised, four-step problem-solving technique (including: identifying specific barriers to adherence, brainstorming solutions with the patient, appraising the options together to choose the best solution, and then subsequent amendment of the intervention based on its impact). A sample of 333 adults with moderate or severe persistent asthma were recruited from low-income urban neighbourhoods and were both reimbursed for participation and supplied the inhaled corticosteroid (ICS) free of charge. Patients were randomised to participate in four 30-min sessions of community based standard asthma education or individualised problem solving over 3 months, and then followed up for a further 3 months. Adherence was monitored electronically. The overall mean adherence was "relatively good" at $61 \pm 27 \%$, although it declined over the study period by $14 \%$ in the usual care group and $10 \%$ in the intervention group. In spite of this decline, there was a statistically significant improvement for both groups in the six-item asthma control questionnaire (ACQ6) [53], quality of life (AQLQ) [54], and percentage predicted forced expiratory volume in $1 \mathrm{~s}$, but no difference in emergency department attendances or hospitalisations. The investigators concluded that problem-solving does not improve adherence or decrease asthma morbidity; however, it may be that the benefit of such an intervention was lost within them addressing a primary (opportunity) barrier to adherence, treatment affordability, and it may also reflect that the "standard" asthma education addressed crucial capability barriers.

A randomised controlled trial by CHRISTAKIS et al. [55] aimed to test whether an interactive website that prompted parents to assess their child's asthma and gave tailored feedback and advice on adherence strategies could improve self-reported ICS adherence for children with asthma. 603 eligible patients (29\% classified as having mild to severe persistent asthma, $71 \%$ mild intermittent asthma) were randomised to the intervention monthly for 6 months, while the control group completed a non-asthma related questionnaire at the same frequency. Both groups received vouchers for participation for the first 6 months, and were then offered an optional additional non-incentivised 6 months. Overall, $85 \%$ of parents completed the 6 -month assessment and $80 \%$ completed the full year, suggesting that the incentive was not a key driver of participation for either group. Interestingly, the intervention had no impact when considering patients who were not using a controller therapy at baseline but should have been (non-initiators). However, in patients who were already using a controller medicine at baseline, the intervention group had greater adherence at 6 months, but this did not persist, so there was no discernible difference between groups at 12 months. There were no differences in asthma-related quality of life measures between groups at either time-point. The reasonable conclusion was that a tailored interactive website could increase ICS adherence, but only during the period of active intervention, and that this change was not associated with improvements in patient-reported quality of life. 
JANSON et al. [56] conducted a randomised prospective trial of 84 patients with moderatesevere persistent asthma who were recruited from private and public community clinics. They investigated the impact on ICS adherence and asthma control of "usual care" versus a programme of three 30-min, individualised, self-management face-to-face education sessions that included: asthma information, inhaler technique optimisation, agreement of an action plan and trigger avoidance strategies with support to self-monitor symptoms and peak flow. These consultations were delivered bi-weekly over 4 weeks, with follow-up observation for a further 14 weeks. ICS adherence was measured electronically and categorised as $\geq 60 \%$ or $<60 \%$ adherence to prescribed doses. Participants were reimbursed for their time and received their ICS free-of-charge. The 45 participants who were randomised to receive the self-management intervention maintained a consistently higher ICS adherence level than the control group. Interestingly, the effect was more pronounced at the end of the 4-week intervention period, a nine-fold increase in the odds of $\geq 60 \%$ adherence compared with control, compared with threefold greater odds at the end of the study. This improvement also affected outcomes, including improvement in perceived control of asthma, decreased night-time awakenings and decreased inhaled $\beta_{2}$-agonist use, but also highlights the relatively limited impact of a discrete intervention on promoting persistence with treatment.

\section{Reminders}

Non-initiation or primary medication nonadherence (PMN) is defined as patients not picking up a first prescription. FISCHER et al. [57] investigated whether a telephone call intervention from the physician's office to patients who had not picked up new prescriptions after three phone calls from the pharmacy, would have an effect. Patients receiving new prescriptions for medications treating asthma, hypertension, diabetes or hyperlipidaemia were identified, and as part of an existing programme received two automated and one live call from the pharmacy encouraging them to pick up their prescription. Those who cancelled their prescriptions or had not picked them up after the third pharmacy call were eligible for this study. 148 patients were randomised to no further follow-up and 142 to the intervention group, which received a telephone call from a nurse to assess reasons for PMN and encourage pickup of prescriptions. Up to three attempts were made to reach each patient by the nurse. Initial PMN rates in the overall population were lower than similar studies at $6 \%$, and the intervention did not change subsequent collection rates: $25 \%$ of intervention patients, $24 \%$ control patients. This suggests that the pharmacist's initial efforts were effective, confirms that additional similar reminders will not increase collection further and that the residual PMN was unlikely to be because the patient had forgotten.

Julious et al. [58] recognised that the return to school in September was associated with a peak in asthma episodes in school-aged children and postulated that this was linked to the observed fall in prescription collection in August. They therefore investigated the impact of writing to parents/carers in August reminding them of the importance of medication taking and ensuring sufficient treatment supply prior to returning to school. In August, the proportion of children who collected prescriptions increased (odds ratio 1.43), as did scheduled contacts (OR: 1.13); however, in September the proportion of children who had an unscheduled medical contact increased (OR: 1.09). The reasons for the apparent lack of translation into a September benefit were unclear.

A study by Foster et al. [59] investigated the change in ICS/long-acting $\beta$-agonist (LABA) adherence (monitored electronically) of 143 patients with moderate-severe asthma. The interventions were: general practitioner (GP)-delivered usual care, GP-delivered personalised adherence discussion (PAD), and an inhaler reminder (provided if doses were missed) with adherence feedback (IRF). Patients were randomised to receive usual care, PAD, IRF, or IRF plus PAD and the effect on asthma control was measured using the Asthma Control Test (ACT) [60]. After 6 months, adherence was significantly higher in the IRF group than in nonIRF groups ( $73 \pm 26 \%$ versus $46 \pm 28 \%$ of prescribed daily doses; $p<0.0001$ ), but not between PAD and non-PAD groups. Asthma control improved overall (mean change in ACT score 4.5 $\pm 4.9 ; \mathrm{p}<0.0001$ ), but there was no significant difference among groups. The authors concluded that inhaler reminders may improve patients adherence in primary care compared with a behavioural intervention or usual care alone, but that this may not translate into an improvement in asthma control.

\section{Adapting services}

Following the implementation of a four-phase asthma management programme in Quebec province, Canada, GuÉnETTE et al. [61] evaluated the "integrated care" intervention (described as "a process to ensure that services provided by HCPs from different organisations are mapped and linked to the particular needs of each individual") versus "usual care". Patients aged 12-45 years were recruited from pharmacies, with 108 patients participating in the programme and 241 not exposed to it. Asthma control was measured using the ACQ5 (score $\geq 1.5$ indicates inadequately controlled asthma) [62], and ICS adherence was assessed using the Morisky medication adherence scale (MMAS-4) [63] and the medication possession ratio (MPR) [64]. At baseline, the proportion of 
participants with "good" ICS adherence (MMAS-4 of zero or MPR $\geq 75 \%$ ) was low in both groups: $15.8 \%$ and $9.1 \%$, respectively. After 12 months, only the exposed participants showed an improvement in adherence measured by MMAS- 4 and by MPR, however, asthma control improved significantly within both groups (no significant difference seen between groups). This result may be because all participants received an asthma action plan and peak flow meter at recruitment, but also because participation in the programme was reported as low. The authors concluded that an integrated intervention, with HCPs collaborating to optimise asthma control can improve ICS adherence, but correctly pointed out that although statistically significant, the actual improvements for individuals were modest, and thus, did not translate into better asthma control.

The devastating effect of undertreated tuberculosis and therefore the need to guarantee adherence in some patient groups through directly observed therapy, has been recognised for over 20 years [65]. In a similar type of intervention, HARRINGTON et al. [66] investigated the administration of ICS doses to 46 disadvantaged school children with asthma over a 60-day period. The intervention group $(n=19)$ had the morning ICS dose administered by the school nurse, with other doses given by the parent as usual, while the control group had all doses administered by the parent. Adherence was calculated from nurse- and parent-reported doses administered. Children in the intervention group received $91.7 \%$ of expected morning doses of ICS (some doses missed due to school absences), but interestingly, there was no significant difference between groups for number of morning doses or evening doses taken. Despite this, the intervention group reported significantly less functional limitation, better adjustment to family life, and less parent sleep loss than control patients at the end of the study period. This methodology probably facilitated an overestimation of home administration, but the usefulness of the strategy is more limited by an inability to sustain this intervention long term or apply on a larger scale and the lack of longer term support for patients/parents to take ownership of adherence, a particular problem for older children and young adults [67-71].

\section{Electronic adherence monitoring and feedback}

It seems logical that novel studies using an objective assessment of adherence (e.g. an electronic inhaler device) versus traditional measures (self-reported adherence or prescription collection information), would deliver more accurate results. SULAIMAN et al. [72] recognised that in difficult-to-treat asthma, poor control could reflect suboptimal medication adherence (infrequent dose administration and/or poor inhaler technique), or genuinely severe refractory asthma. They tested their hypothesis that regular visual "(bio)feedback" to the patient on their specific adherence components would improve adherence, by recruiting patients under a hospital clinic with uncontrolled asthma to receive intensive education (including repeated training in inhaler use, adherence and disease management), with or without (bio)feedback. The primary outcome was inhaler adherence, and the secondary outcomes included clinical outcomes (assessed using peak expiratory flow, ACT and AQLQ). The mean rate of adherence during the third (final) month in the (bio) feedback group $(n=111)$ was significantly higher than that in the group receiving intensive education alone ( $n=107 ; 73 \%$ versus $63 \%$ ), although both rates were higher than previous similar studies, which the authors attributed to the effectiveness of their intensive education programme. At the end of the study, asthma was stable or improved in 54 patients (38\%); uncontrolled, with adherence $<80 \%$ in 52 (35\%); and uncontrolled, but adherence $>80 \%$ in 40 (27\%). Thus, the results of this study suggest that (bio)feedback of adherence and intensive education are superior to intensive education alone in supporting persistence with medicines, and facilitates clinicians identifying patients as refractory or in need of further adherence support.

These results are in contrast to a recent study by Moore et al. [73] investigating the effect a clip-on inhaler sensor, a patient-facing app and HCP dashboard. They found that despite a statistically significant increase in ICS adherence of $12 \%$ in the Ellipta-monitored arm, there was no significant difference between groups after 6 months using the ACT score [74]. Whether this reflects a flaw in the ACT as a measure of clinical outcome, that the cohort were sufficiently adherent at the beginning of the study that this absolute increase (equivalent to one additional dose of maintenance medication per week) was unlikely to bring about a readily detectable improvement, or something else, is unclear. It is, however, important that we do not lose faith in the benefit of incremental adherence improvements in individual patients, or underestimate the impact of these devices for facilitating conversations about adherence between clinicians and patients and potentially improving inhaler technique through real-time feedback.

In summary, these studies suggest that adherence may improve with individualised selfmanagement education programmes, by feeding back on inhaler deviations and by providing free prescriptions to those who would otherwise pay, but there is limited evidence to support interventions reminding patients (or their parents) to collect or administer medication, for redesigned services that patients do not engage with or that usurp 
patient/parent responsibility in medicines use. The waning adherence seen over even short periods of time suggests that interventions require regular refreshing to maintain impact $[52,55,56,73]$.

\section{Limitations of improvements in adherence}

Somewhat surprisingly, common themes in adherence are that its improvement does not consistently result in a corresponding improvement in biomarkers, morbidity, mortality, quality of life, patient satisfaction, healthcare use, or costs [73, 75-78], that symptoms do not beget adherence [79] and the effectiveness of seemingly similar treatments may be affected differently by concomitant treatment adherence [80, 81]. A 2017 Cochrane review aimed to assess the efficacy and safety of interventions intended to improve adherence to ICS therapy in asthma [75]. It found that while the pooled results of studies suggested that some interventions could improve adherence, the relevance of this improvement for an individual was less clear. It concluded that this lack of translation of an increase in adherence into better clinical outcomes was most likely due to methodological limitations (including inconsistent measurement of an intervention or objective impact), that in several studies adherence improved in the control and intervention arm, so not really comparing an intervention with "usual care", and the significant risk of bias from inclusion in an adherence trial. The significant risk of bias is that a non-adherent person would be unlikely to agree to participate and the potential for a "Hawthorne effect" (also referred to as the observer effect), where individuals modify or improve an aspect of their behaviour in response to their awareness of being observed. There would appear to be limited capacity to remove this bias from adherence studies, but having a long duration of follow-up may mitigate its influence on results.

At this point, a note of care is required regarding the unintended consequences of the sudden onset adherence, as seen in a study published in the BMJ in 2005 [82]. In this study, investigators aimed to determine the effect of a home-based medication review by pharmacists (that included supporting better adherence) on hospital readmission rates among older people. It found that the intervention was associated with a significantly higher rate of admissions and lead to a cautionary speculative message from the authors was that this "counterintuitive" finding may have been due to an improvement in adherence leading to iatrogenic adverse effects.

In conclusion, we should assume that a degree of non-adherence is present in all of our patients at some time, learn to investigate the reasons

\section{Self-evaluation questions}

1. During your consultation with a person with poorly controlled asthma, she tells you that she doesn't use her ICS as she is concerned that it will cause weight gain. Should you:

a) Change her ICS therapy to a once daily preparation.

b) Stop the ICS and consider other therapeutic options.

c) Reassure her that an ICS will not cause side-effects (e.g. weight gain).

d) Discuss the relative risks and benefits of steroid therapy (oral and inhaled) on management of her asthma.

2. A person with well controlled COPD tells you he sometimes forgets to take his evening medicines. Should you:

a) Change his inhaled therapy to a once daily preparation to take in the morning.

b) Offer him a pharmacy-filled monitored dosage system (e.g. a dosette box).

c) Suggest he set a reminder on his phone and incorporate evening doses into his dinner time or bedtime routine.

d) Acknowledge how difficult it is to remember and reassure him that as he is well controlled currently, it isn't a problem.

3. A gentleman with asthma tells you that he doesn't use his ICS/LABA inhaler as he cannot afford to pay for it and his short-acting $\beta$-agonist. Should you:

a) Suggest that he purchase a pre-payment certificate to allow all prescription items to be free.

b) Recommend a ICS/LABA "maintenance and reliever" regimen.

c) Ask the primary care provider to issue several inhalers on each prescription.

d) Any of the above depending on the individual circumstances.

4. A person tells you that they never miss doses and use their preventer inhalers "religiously"; however, their primary care prescription record suggests that they have only collected salbutamol in the past 6 months. Should you:

a) Tell them that you know this isn't true and show them the prescription record.

b) Refer them to the pharmacist (or other suitably trained healthcare professional) to improve their adherence.

c) Follow them up sooner than planned to re-discuss medicines use.

d) b and c.

behind this without judgement and engage the patient in application of relevant and individualised interventions to improve and maintain adherence. We should appraise the potential risk (current and future) that non-adherence presents to the patient, and be able to discuss this in a way the person can understand. In lieu of wider acceptance in respiratory medicine of brief interventions to address non-adherence (in a similar way as for alcohol and smoking), it follows that HCPs need to develop their own simple, practical and generalisable process, and to regularly review whether the success of the interventions in the short and longer term to maximise clinical outcomes. 


\section{Key points}

- While the extent of suboptimal adherence in chronic respiratory disease and its significant deleterious impact on morbidity and mortality is acknowledged, to date, little has had a significant impact on improving it in practice.

- Clinicians underestimate the extent of non-adherence in their patients and, if they do enquire about adherence in consultations, often do so in ways which make patients unwilling to disclose it.

- There is a paucity of evidence supporting the utility of large-scale interventions to improve long-term adherence, but understanding the reasoning behind non-adherence may help clinicians implement interventions to better support it for an individual.

- Given the tendency to lapse into non-adherent behaviours, adherence should be considered a chronic concern in need of long-term monitoring and on-going support.

\section{Affiliations}

\section{Gráinne d'Ancona' ${ }^{1}$ John Weinman²}

1Pharmacy Dept/Thoracic Medicine, Guy's and St Thomas' NHS Foundation Trust, London, UK. 'Institute of Pharmaceutical Sciences, King's College London, London, UK.

Conflict of interest

G. d'Ancona reports grants, personal fees and non-financial support (conference attendance) from AstraZeneca, personal fees and non-financial support (conference attendance) from Boehringer Ingelheim, grants, personal fees and non-financial support (conference attendance) from Chiesi, grants and personal fees from GSK, personal fees and non-financial support (conference attendance) from Sanofi, outside the submitted work. J. Weinman reports consultancy for Atlantis Healthcare, who provide patient adherence support programmes.

\section{References}

1. World Health Organization (WHO). Adherence to Long-Term Therapies - Evidence for Action. 2003. www.who.int/chp/ knowledge/publications/adherence_report/en/

2. Haynes RB, Ackloo E, Sahota N, et al. Interventions for enhancing medication adherence. Cochrane Database Syst Rev 2008; 2: CD000011.

3. Holmes J, Heaney LG. Measuring adherence to therapy in airways disease. Breathe 2021; 17: 210037.

4. Brennan V, Mulvey C, Costello RW. The clinical impact of adherence to therapy in airways disease. Breathe 2021; 17 : 210039.

5. van Boven JFM, Lavorini F, Dekhuijzen PNR, et al. Urging Europe to put non-adherence to inhaled respiratory medication higher on the policy agenda: a report from the First European Congress on Adherence to Therapy. Eur Respir J 2017; 49: 1700076

6. Bloom Cl, Douglas I, Olney J, et al. Cost saving of switching to equivalent inhalers and its effect on health outcomes. Thorax 2019; 74: 1078-1086.

7. Vrijens B, De Geest S, Hughes DA, et al. A new taxonomy for describing and defining adherence to medications. Br J Clin Pharmacol 2012; 73: 691-705.
8. Glackin SN, d'Ancona G. Ethical, philosophical, and practical considerations in adherence to therapy in sleep medicine. Curr Opin Pulm Med 2019; 25: 609-613.

9. Engel T, Ungar B, Ben-Haim G, et al. Re-phrasing the question: a simple tool for evaluation of adherence to therapy in patients with inflammatory bowel disease. United European Gastroenterol J 2017; 5: 880-886.

10. National Institute for Health and Clinical Excellence (NICE). Clinical Guideline [CG76]. Medicines Adherence: Involving Patients in Decisions About Prescribed Medicines and Supporting Adherence. London, NICE, 2009. www.nice.org.uk/guidance/ cg76

11. Horne R, Cooper V, Wileman V, et al. Supporting adherence to medicines for long-term conditions. Eur Psychol 2019; 24: 82-96.

12. Meddings J, Kerr EA, Heisler M, et al. Physician assessments of medication adherence and decisions to intensify medications for patients with uncontrolled blood pressure: still no better than a coin toss. BMC Health Serv Res 2012; 12: 270 .

13. Khan R, Socha-Dietrich K. Investing in medication adherence improves health outcomes and health system efficiency. OECD 
Health Working Papers, No. 105. OECD Publishing, Paris, 2018. https://doi.org/10.1787/8178962c-en

14. Clyne W, McLachlan S, Mshelia C, et al. "My patients are better than yours": optimistic bias about patients' medication adherence by European health care professionals. Patient Prefer Adherence 2016; 10: 1937-1944.

15. Paterson DL, Swindells S, Mohr J, et al. Adherence to protease inhibitor therapy and outcomes in patients with HIV infection. Ann Intern Med 2000; 133: 21-30.

16. Gillespie SH, Crook AM, McHugh TD, et al. Four-month moxifloxacin-based regimens for drug-sensitive tuberculosis. N EnglJ Med 2014; 371: 1577-1587.

17. Merle CS, Fielding K, Sow OB, et al. A four-month gatifloxacincontaining regimen for treating tuberculosis. $N$ Engl / Med 2014; 371: 1588-1598.

18. Imperial MZ, Nahid P, Phillips PPJ, et al. A patient-level pooled analysis of treatment-shortening regimens for drugsusceptible pulmonary tuberculosis. Nat Med 2018; 24: 1708-1715.

19. Kribbs NB, Pack Al, Kline LR, et al. Objective measurement of patterns of nasal CPAP use by patients with obstructive sleep apnea. Am Rev Respir Dis 1993; 147: 887-895.

20. Bollig SM. Encouraging CPAP adherence: it is everyone's job. Respir Care 2010; 55: 1230-1239.

21. Heaney LG, Horne R. Non-adherence in difficult asthma: time to take it seriously. Thorax 2012; 67: 268-270.

22. Robinson DS, Kariyawasam HH, Heaney LG. Phase three studies of biologics for severe asthma: could do better? Eur RespirJ 2017; 50: 1701108.

23. Gadkari AS, McHorney CA. Unintentional non-adherence to chronic prescription medications: how unintentional is it really? BMC Health Serv Res 2012; 12: 98.

24. Chrystyn H, Price D. Not all asthma inhalers are the same: factors to consider when prescribing an inhaler. Prim Care Respir J 2009; 18: 243-249.

25. Price DB, Román-Rodríguez M, McQueen RB, et al. Inhaler Errors in the CRITIKAL study: type, frequency, and association with asthma outcomes. J Allergy Clin Immunol Pract 2017; 5: 1071-1081.

26. Sulaiman I, Cushen B, Greene G, et al. Objective assessment of adherence to inhalers by patients with chronic obstructive pulmonary disease. Am J Respir Crit Care Med 2017; 195: 1333-1343.

27. Chrystyn H, Audibert R, Keller M, et al. Real-life inhaler adherence and technique: time to get smarter! Respir Med 2019; 158: 24-32.

28. Normansell R, Kew KM, Mathioudakis AG. Interventions to improve inhaler technique for people with asthma. Cochrane Database Syst Rev 2017; 3: CD012286.

29. Volerman A, Carpenter D, Press V. What can be done to impact respiratory inhaler misuse: exploring the problem, reasons, and solutions. Expert Rev Respir Med 2020; 14: 791-805.

30. van Boven JFM, Cushen B, Sulaiman I, et al. Personalising adherence-enhancing interventions using a smart inhaler in patients with COPD: an exploratory cost-effectiveness analysis. NPJ Prim Care Respir Med 2018; 28: 24.

31. Cushen B, Sulaiman I, Greene G, et al. The clinical impact of different adherence behaviors in patients with severe chronic obstructive pulmonary disease. Am J Respir Crit Care Med 2018; 197: 1630-1633.

32. Bosnic-Anticevich S, Chrystyn H, Costello RW, et al. The use of multiple respiratory inhalers requiring different inhalation techniques has an adverse effect on COPD outcomes. Int $J$ Chron Obstruct Pulmon Dis 2017; 12: 59-71.

33. Alotaibi S, Hassan WM, Alhashimi H. Concurrent use of metered dose inhalers without spacer and dry powder inhalers by asthmatic children adversely affect proper inhalation technique. Internet J Pediatr Neonatol 2011; 13: 29.

34. Price D, Chrystyn H, Kaplan A, et al. Effectiveness of same versus mixed asthma inhaler devices: a retrospective observational study in primary care. Allergy Asthma Immunol Res 2012; 4: 184-191.

35. Ley P. Satisfaction, compliance and communication. BrJ Clin Psychol 1982; 21: 241-254.
36. Michie S, van Stralen MM, West R. The behaviour change wheel: a new method for characterising and designing behaviour change interventions. Implement Sci 2011; 6: 42.

37. Jackson C, Eliasson L, Barber N, et al. Applying COM-B to medication adherence: a suggested framework for research and interventions. European Health Psychologist 2014; 16: 7-17.

38. Choudhry NK, Krumme AA, Ercole PM, et al. Effect of reminder devices on medication adherence: the REMIND randomized clinical trial. JAMA Intern Med 2017; 177: 624-631.

39. Allemann SS, Nieuwlaat R, van den Bemt BJ, et al. Matching adherence interventions to patient determinants using the theoretical domains framework. Front Pharmacol 2016; 7: 429.

40. Weinman J, Ali I, Hodgkinson A, et al. Pilot testing of a brief pre-consultation screener for improving the identification and discussion of medication adherence in routine consultations. Patient Prefer Adherence 2019; 13: 1895-1898.

41. Horne R, Chapman SC, Parham R, et al. Understanding patients' adherence-related beliefs about medicines prescribed for long-term conditions: a meta-analytic review of the Necessity-Concerns Framework. PLoS One 2013; 8: e80633.

42. Ryan R, Santesso N, Lowe $D$, et al. Interventions to improve safe and effective medicines use by consumers: an overview of systematic reviews. Cochrane Database Syst Rev 2014; 4 : CD007768.

43. George M, Bender B. New insights to improve treatment adherence in asthma and COPD. Patient Prefer Adherence 2019; 13: 1325-1334

44. van Boven JFM, Ryan D, Eakin MN, et al. Enhancing respiratory medication adherence: the role of health care professionals and cost-effectiveness considerations. J Allergy Clin Immunol Pract 2016; 4: 835-846

45. Horne R. Compliance, adherence, and concordance: implications for asthma treatment. Chest 2006; 130: 65S-72S.

46. Lemay KS, Saini B, Bosnic-Anticevich S, et al. An exploration of clinical interventions provided by pharmacists within a complex asthma service. Pharm Pract (Granada) 2015; 13: 529.

47. Mes MA, Katzer CB, Chan AHY, et al. Pharmacists and medication adherence in asthma: a systematic review and meta-analysis. Eur Respir J 2018; 52: 1800485

48. Hudd TR. Emerging role of pharmacists in managing patients with chronic obstructive pulmonary disease. Am J Health Syst Pharm 2020; 77: 1625-1630.

49. Bryant J, McDonald VM, Boyes A, et al. Improving medication adherence in chronic obstructive pulmonary disease: a systematic review. Respir Res 2013; 14: 109.

50. Davis E, Marra C, Gamble JM, et al. Effectiveness of a pharmacist-driven intervention in COPD (EPIC): study protocol for a randomized controlled trial. Trials 2016; 17: 502

51. O'Dwyer SM, MacHale E, Sulaiman I, et al. The effect of providing feedback on inhaler technique and adherence from an electronic audio recording device, INCA $®$, in a community pharmacy setting: study protocol for a randomised controlled trial. Trials 2016; 17: 226.

52. Apter AJ, Wang X, Bogen DK, et al. Problem solving to improve adherence and asthma outcomes in urban adults with moderate or severe asthma: a randomized controlled trial. J Allergy Clin Immunol 2011; 128: 516-523.

53. Juniper EF, Bousquet J, Abetz L, et al. Identifying 'wellcontrolled' and 'not well-controlled' asthma using the Asthma Control Questionnaire. Respir Med 2006; 100: 616-621.

54. Juniper EF, Guyatt GH, Ferrie PJ, et al. Measuring quality of life in asthma. Am Rev Respir Dis 1993; 147: 832-838.

55. Christakis DA, Garrison MM, Lozano P, et al. Improving parental adherence with asthma treatment guidelines: a randomized controlled trial of an interactive website. Acad Pediatr 2012; 12: 302-311.

56. Janson SL, McGrath KW, Covington JK, et al. Individualized asthma self-management improves medication adherence and markers of asthma control. J Allergy Clin Immunol 2009; 123: $840-846$

\section{Suggested answers}

1. d.

2. Potentially a or c, depending on patient preference.

3. d.

4. d. 
57. Fischer MA, Jones JB, Wright E, et al. A randomized telephone intervention trial to reduce primary medication nonadherence. J Manag Care Spec Pharm 2015; 21: 124-131.

58. Julious S, Horspool M, Davis S, et al. PLEASANT: Preventing and Lessening Exacerbations of Asthma in School-age children Associated with a New Term - a cluster randomised controlled trial and economic evaluation. Health Technol Assess 2016 20: 1-154.

59. Foster JM, Usherwood T, Smith L, et al. Inhaler reminders improve adherence with controller treatment in primary care patients with asthma. J Allergy Clin Immunol 2014; 134 1260-1268.e3.

60. Schatz M, Sorkness CA, Li JT, et al. Asthma Control Test: reliability, validity, and responsiveness in patients not previously followed by asthma specialists. J Allergy Clin Immunol 2006; 117: 549-556.

61. Guénette L, Breton M-C, Grégoire J-P, et al. Effectiveness of an asthma integrated care program on asthma control and adherence to inhaled corticosteroids. J Asthma 2015; 52: 638-645.

62. Juniper EF, O’Byrne PM, Roberts JN. Measuring asthma control in group studies: do we need airway calibre and rescue beta2agonist use? Respir Med 2001; 95: 319-323.

63. Morisky DE, Ang A, Krousel-Wood M, et al. Predictive validity of a medication adherence measure in an outpatient setting J Clin Hypertens (Greenwich, Conn) 2008; 10: 348-354.

64. Lam WY, Fresco P. Medication adherence measures: an overview. Biomed Res Int 2015; 2015: 217047.

65. Blumberg HM, Burman WJ, Chaisson RE, et al. American Thoracic Society/Centers for Disease Control and Prevention/Infectious Diseases Society of America: treatment of tuberculosis. Am J Respir Crit Care Med 2003; 167: 603-662

66. Harrington $C B$, Langhans $E$, Shelef $D Q$, et al. A pilot randomized trial of school-based administration of inhaled corticosteroids for at-risk children with asthma. J Asthma 2018; 55: 145-151.

67. Dinwiddie R, Müller WG. Adolescent treatment compliance in asthma. J R Soc Med 2002; 95: 68-71.

68. Engelkes M, Janssens HM, de Jongste JC, et al. Prescription patterns, adherence and characteristics of non-adherence in children with asthma in primary care. Pediatr Allergy Immunol 2016; 27: 201-208

69. Kaplan A, Price D. Treatment adherence in adolescents with asthma. J Asthma Allergy 2020; 13: 39-49.
70. Morton RW, Everard ML, Elphick HE. Adherence in childhood asthma: the elephant in the room. Arch Dis Child 2014; 99 949-953.

71. Sleath B, Gratie D, Carpenter D, et al. Reported problems and adherence in using asthma medications among adolescents and their caregivers. Ann Pharmacother 2018; 52: 855-861.

72. Sulaiman I, Greene G, MacHale E, et al. A randomised clinical trial of feedback on inhaler adherence and technique in patients with severe uncontrolled asthma. Eur Respir J 2018; 51: 1701126.

73. Moore A, Preece A, Sharma R, et al. A randomised controlled trial of the effect of a connected inhaler system on medication adherence in uncontrolled asthmatic patients. Eur Respir 2021; 57: 2003103

74. Nathan RA, Sorkness CA, Kosinski M, et al. Development of the asthma control test: a survey for assessing asthma control. J Allergy Clin Immunol 2004; 113: 59-65.

75. Normansell R, Kew KM, Stovold E. Interventions to improve adherence to inhaled steroids for asthma. Cochrane Database Syst Rev 2017; 4: CD012226.

76. Petsky HL, Kew KM, Chang AB. Exhaled nitric oxide levels to guide treatment for children with asthma. Cochrane Database Syst Rev 2016; 11: CD011439.

77. Viswanathan M, Golin CE, Jones CD, et al. Interventions to improve adherence to self-administered medications for chronic diseases in the United States: a systematic review. Ann Intern Med 2012; 157: 785-795.

78. Petsky HL, Cates CJ, Kew KM, et al. Tailoring asthma treatment on eosinophilic markers (exhaled nitric oxide or sputum eosinophils): a systematic review and meta-analysis. Thorax 2018; 73: 1110-1119.

79. Pérez-Carbonell L, Lyons E, Gnoni V, et al. Adherence to wakefulness promoting medication in patients with narcolepsy. Sleep Med 2020; 70: 50-54.

80. d'Ancona G, Kavanagh J, Roxas C, et al. Adherence to inhaled corticosteroids and clinical outcomes in mepolizumab therapy for severe asthma. Eur Respir J 2020; 55: 1902259.

81. d'Ancona G, Kavanagh JE, Dhariwal J, et al. Adherence to inhaled corticosteroids and clinical outcomes following a year of benralizumab therapy for severe eosinophilic asthma. Allergy 2021; in press [https://doi.org/10.1111/all.14737].

82. Holland R, Lenaghan E, Harvey I, et al. Does home based medication review keep older people out of hospital? The HOMER randomised controlled trial. BMJ 2005; 330: 293. 